\title{
Study of ionospheric anomalies due to impact of typhoon using Principal Component Analysis and image processing
}

\author{
JYH-WOEI LIN \\ Department of Earth Science, National Cheng Kung University, No. 1 University Road, Tainan City, Taiwan. \\ e-mail:pgjwl1966@gmail.com
}

Principal Component Analysis (PCA) and image processing are used to determine Total Electron Content (TEC) anomalies in the F-layer of the ionosphere relating to Typhoon Nakri for 29 May, 2008 (UTC). PCA and image processing are applied to the global ionospheric map (GIM) with transforms conducted for the time period 12:00-14:00 UT on 29 May, 2008 when the wind was most intense. Results show that at a height of approximately 150-200 km the TEC anomaly is highly localized; however, it becomes more intense and widespread with height. Potential causes of these results are discussed with emphasis given to acoustic gravity waves caused by wind force.

\section{Introduction}

One of the benefits of using Global Positioning System (GPS) satellites in precision geodetic measurement has been the ability to measure Total Electron Content (TEC) in the ionosphere through phase and code measurements of signal delay between receivers and satellites. Furthermore, continued development of dense ground-receiver networks has allowed for $2 \mathrm{D}$ and $3 \mathrm{D}$ imaging of dynamic changes in ionospheric plasma. One potential area of application is in the study of typhoon related TEC anomalies. The association between typhoon activity and TEC anomalies dates back to the work of Bauer (1958) who noticed that the $\mathrm{F}_{\mathrm{o}} \mathrm{F}_{2}$ region of the ionosphere would rise and reach its maximum height just before the arrival of a typhoon at the observation station. Other more recent research has also noted fluctuations in the $\mathrm{F}_{\mathrm{o}} \mathrm{F}_{2}$ layer as typhoons approach (Shen 1982; Liu et al. 2006a, 2006b). Huang et al. (1985) researched 15 typhoons throughout 1982 and 1983 near Taiwan using a real-time High Frequency (HF) Doppler frequency-shift sounding array to detect ionospheric Doppler frequency shifts (DFS) induced by typhoons. Among their results, two typhoons, Wayne and Andy, caused significant ionospheric variations, which were attributable to typhoon-generated acoustic gravity waves. These were detected by the sounding system. In a more recent study, Mao et al. (2009) found that anomalous TEC behaviour relating to typhoon Matsa could be distinguished using a GPS-TEC map based on 50 GPS stations covering the International Global Navigational Satellite Systems Service (IGS) GPS tracking network, Crustal Motion Observation Network of China (CMONOC) GPS tracking network, and Shanghai GPS tracking network from June 30 to August 19, 2005. Their analysis showed that TEC increased before the landing of typhoon Matsa, with TEC increasing from its monthly median over the typhoon area by

Keywords. Principal Component Analysis; total electron content; global ionospheric map; acoustic gravity waves. 
about 5 TEC units $\left(1 \mathrm{TECu}=10^{16}\right.$ electron $\left./ \mathrm{m}^{2}\right)$. The magnitude and area of the increased-TEC decreased with the landing of the typhoon. One day after the passage of the typhoon, TEC reached a minimum and was lower than its monthly median. Kazimirovsky et al. (2003) provides an excellent review of the state of knowledge as of 2003 on the potential causes of ionospheric anomalies from anthropogenic causes through to the weather and other natural phenomena. Explanations as to the cause of typhoon-related TEC anomalies include typhoon-generated acoustic gravity waves and

Table 1. Japan Meteorological Agency Best Track Data Correction Date: 07-07-2008.

\begin{tabular}{|c|c|c|c|c|c|c|c|}
\hline Year & Month & Day & Hour & Lat. & Long. & $\begin{array}{c}\text { Pressure } \\
(\mathrm{hPa})\end{array}$ & $\begin{array}{c}\text { Wind } \\
(\mathrm{kt})\end{array}$ \\
\hline 2008 & 5 & 26 & 6 & 10.5 & 140.4 & 1008 & 0 \\
\hline 2008 & 5 & 26 & 12 & 11.7 & 139.3 & 1010 & 0 \\
\hline 2008 & 5 & 26 & 18 & 12.6 & 138.6 & 1008 & 0 \\
\hline 2008 & 5 & 27 & 0 & 13.7 & 138.0 & 1006 & 0 \\
\hline 2008 & 5 & 27 & 6 & 14.3 & 137.6 & 1000 & 35 \\
\hline 2008 & 5 & 27 & 12 & 14.3 & 137.4 & 996 & 40 \\
\hline 2008 & 5 & 27 & 18 & 14.4 & 137.2 & 990 & 45 \\
\hline 2008 & 5 & 28 & 0 & 14.8 & 137.1 & 985 & 55 \\
\hline 2008 & 5 & 28 & 6 & 15.5 & 136.8 & 980 & 65 \\
\hline 2008 & 5 & 28 & 12 & 15.8 & 136.7 & 970 & 70 \\
\hline 2008 & 5 & 28 & 18 & 16 & 136.6 & 955 & 80 \\
\hline 2008 & 5 & 29 & 0 & 16 & 136.3 & 950 & 85 \\
\hline 2008 & 5 & 29 & 6 & 16.2 & 135.8 & 940 & 95 \\
\hline 2008 & 5 & 29 & 12 & 16.2 & 135.5 & 930 & 100 \\
\hline 2008 & 5 & 29 & 18 & 16.4 & 135.1 & 930 & 100 \\
\hline 2008 & 5 & 30 & 0 & 16.6 & 134.7 & 930 & 100 \\
\hline 2008 & 5 & 30 & 6 & 17 & 134.1 & 940 & 95 \\
\hline 2008 & 5 & 30 & 12 & 17.3 & 133.5 & 950 & 85 \\
\hline 2008 & 5 & 30 & 18 & 17.9 & 133 & 960 & 80 \\
\hline 2008 & 5 & 31 & 0 & 18.4 & 132.8 & 965 & 75 \\
\hline 2008 & 5 & 31 & 6 & 19.2 & 132.8 & 970 & 70 \\
\hline 2008 & 5 & 31 & 12 & 19.7 & 132.8 & 970 & 65 \\
\hline 2008 & 5 & 31 & 18 & 20.2 & 132.8 & 970 & 65 \\
\hline 2008 & 6 & 1 & 0 & 20.6 & 132.9 & 970 & 70 \\
\hline 2008 & 6 & 1 & 6 & 21.5 & 133.1 & 970 & 70 \\
\hline 2008 & 6 & 1 & 12 & 22.3 & 133.3 & 970 & 70 \\
\hline 2008 & 6 & 1 & 18 & 23.5 & 133.6 & 965 & 75 \\
\hline 2008 & 6 & 2 & 0 & 25.1 & 134.4 & 960 & 75 \\
\hline 2008 & 6 & 2 & 6 & 26.8 & 135.5 & 960 & 75 \\
\hline 2008 & 6 & 2 & 12 & 28.3 & 137.1 & 965 & 75 \\
\hline 2008 & 6 & 2 & 18 & 29.9 & 138.7 & 970 & 70 \\
\hline 2008 & 6 & 2 & 21 & 30.8 & 139.5 & 975 & 60 \\
\hline 2008 & 6 & 3 & 0 & 31.5 & 140.3 & 980 & 55 \\
\hline 2008 & 6 & 3 & 3 & 32.1 & 141.1 & 985 & 50 \\
\hline 2008 & 6 & 3 & 6 & 32.8 & 142.3 & 990 & 0 \\
\hline 2008 & 6 & 3 & 12 & 33 & 144.3 & 994 & 0 \\
\hline 2008 & 6 & 3 & 18 & 33.4 & 146.8 & 996 & 0 \\
\hline 2008 & 6 & 4 & 0 & 33.4 & 149.4 & 1000 & 0 \\
\hline 2008 & 6 & 4 & 6 & 33.2 & 151.7 & 1004 & 0 \\
\hline 2008 & 6 & 4 & 12 & 32.6 & 154.4 & 1004 & 0 \\
\hline 2008 & 6 & 4 & 18 & 31.7 & 158.2 & 1006 & 0 \\
\hline 2008 & 6 & 5 & 0 & 31.2 & 163.9 & 1008 & 0 \\
\hline 2008 & 6 & 5 & 6 & 30.9 & 167.2 & 1008 & 0 \\
\hline 2008 & 6 & 5 & 12 & 31 & 172.9 & 1008 & 0 \\
\hline 2008 & 6 & 5 & 18 & 31.7 & 176.8 & 1008 & 0 \\
\hline 2008 & 6 & 6 & 0 & 33 & 181 & 1008 & 0 \\
\hline
\end{tabular}




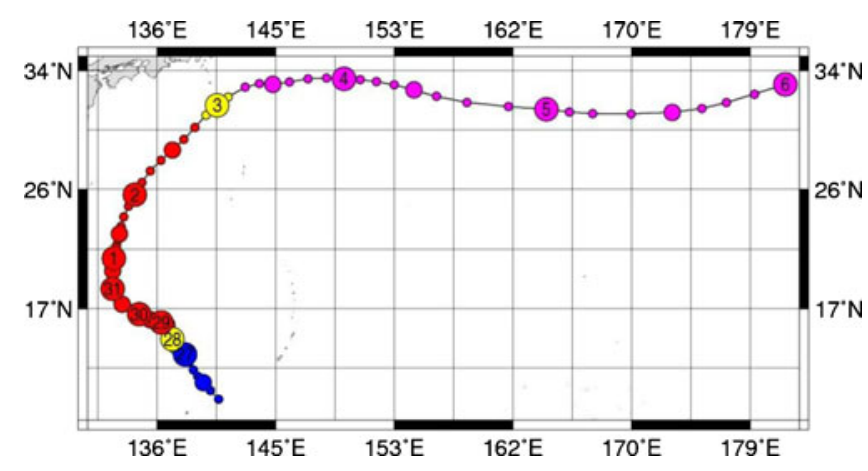

Figure 1. The route of typhoon Nakri. The time is UTC.
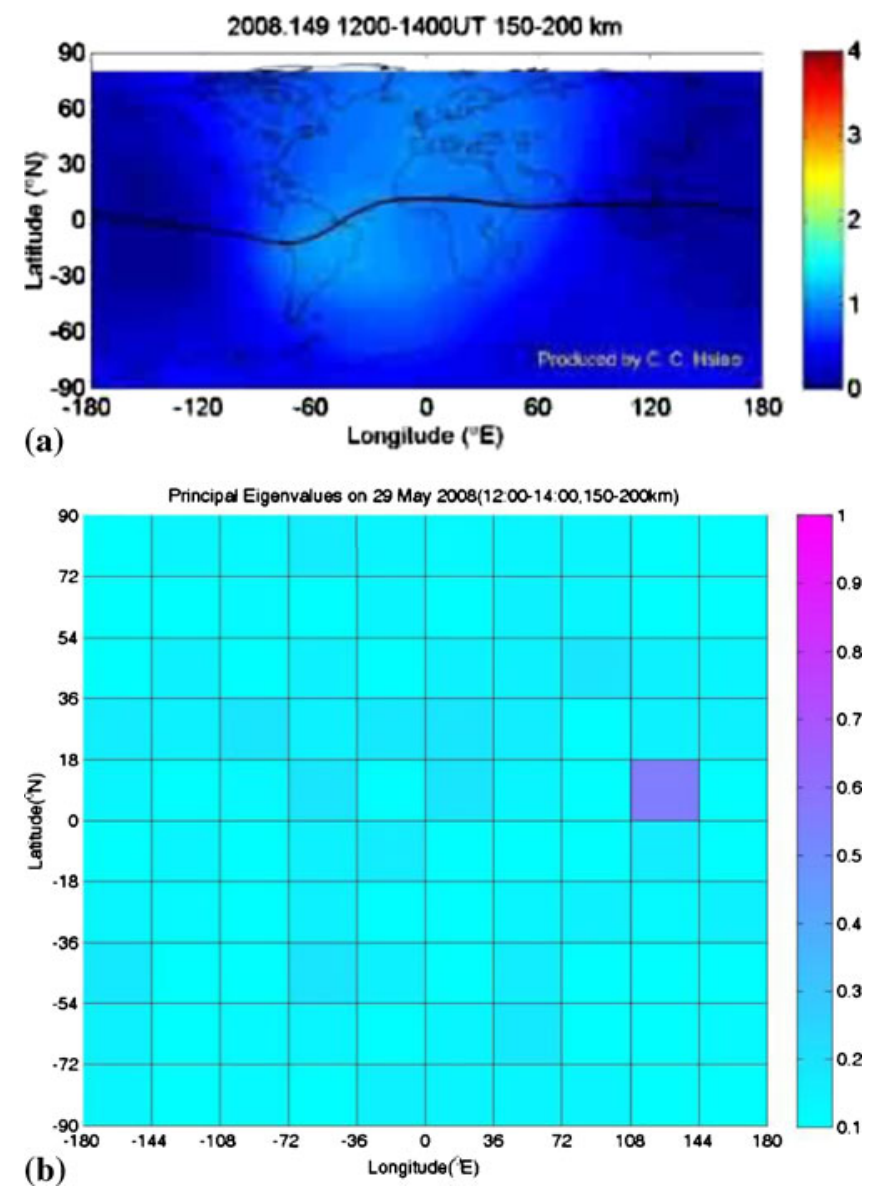

Figure 2. (a) GIM on 29 May at height $150-200 \mathrm{~km}$ for the time period 12:00-14:00 UT. Units for the colour bar of this GIM and later GIMs are TECu and (b) colour-coded scale of the magnitudes of principal eigenvalues corresponding to (a). The colours within grids denote the magnitudes of principal eigenvalue corresponding to (a). There are 100 principal eigenvalues assigned with each grid in the bottom figures representing one principal eigenvalue.

internal gravity waves (IGWs), which are dependent on temperature and wind structure in the atmosphere. Coupling between typhoon processes and the ionosphere has been discussed by many researchers in recent times (Kazimirovsky 2002; Sun et al. 2007; Xu et al. 2008; Mao et al. 2009; Liu et al. 2010). These studies of TEC anomalies, however, have been based on observational methods such as deviations from running medians, and not pure mathematical analysis.

In theory, the propagation of internal atmospheric disturbances such as planetary waves, tides and gravity waves into the troposphere and stratosphere creates the momentum necessary to influence the thermosphere/ionosphere (Kazimirovsky et al. 2003). However, there have been few studies demonstrating the coupling between the troposphere and thermosphere/ionosphere. Two researchers Bishop and Straus (2006) investigated more than 10 tropical cyclones (TCs) using GPS occultation data to examine the relationship between ionospheric TEC and TCs. The impact on TEC was measured over a horizontal distance of $2000 \mathrm{~km}$ from the center of the cyclones and the results found that significant scintillation of TEC could be recorded within $1200 \mathrm{~km}$ of a storm center. Lin (2010a, 2011) used PCA to describe

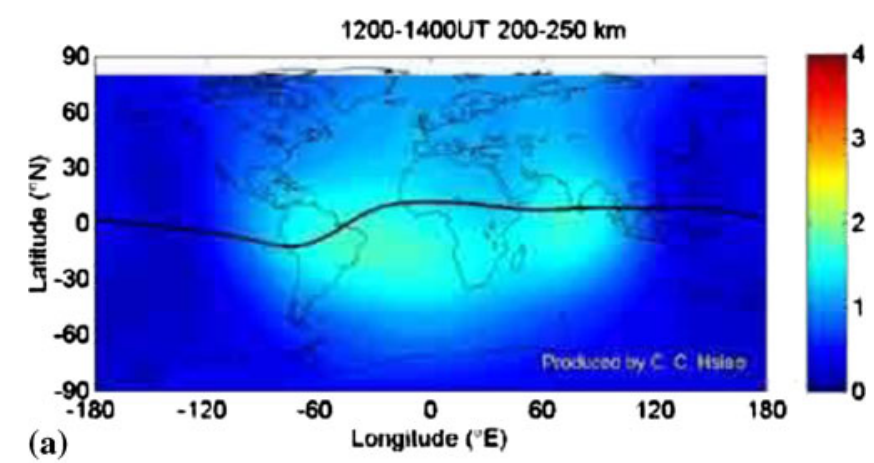

(a)

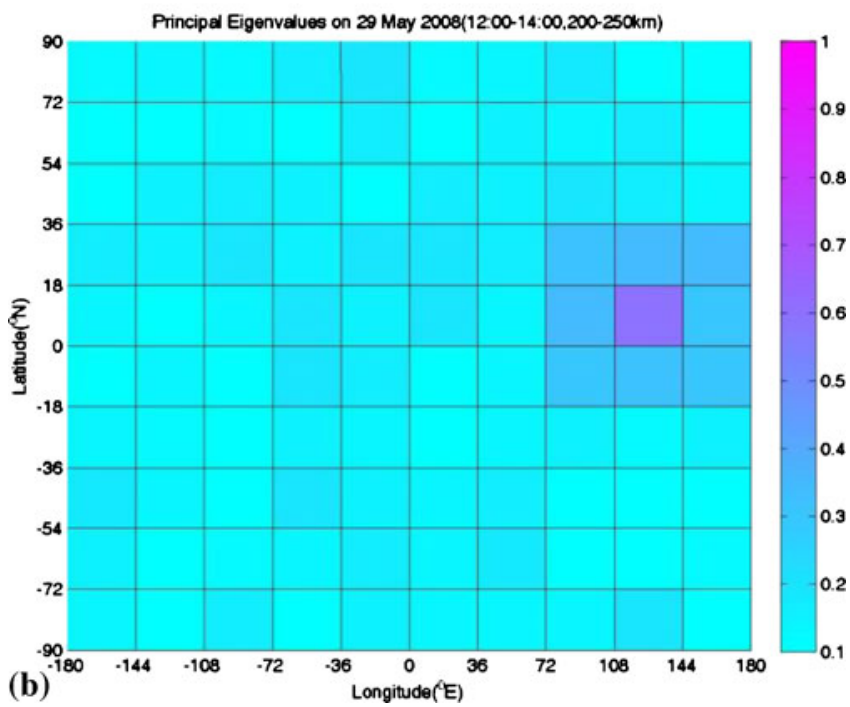

Figure 3. (a) GIM on 29 May at height 200-250 km for time 12:00-14:00 UT and (b) a colour-coded scale of the magnitudes of principal eigenvalues related to (a). 
the spatial distribution of earthquake-related TEC anomalies to the Sichuan basin, Wenchuan, China $M_{w}=7.9$ earthquake of 12 May, 2008. The studies showed the distribution of both a precursor TEC anomaly and a post-earthquake anomaly. For the post-earthquake anomaly, the study found that at lower altitudes $(200 \mathrm{~km})$ the TEC anomaly was spread over a wide range and this range declined with height and the anomaly intensified $(300 \mathrm{~km}$ altitude).

The goal of this paper is to use PCA to look for and examine the spatial distribution of any typhoon-driven ionospheric TEC anomaly associated with typhoon Nakri on 29 May 2008 (UTC). PCA is applied to ionospheric TEC maps at heights ranging from 150 and $450 \mathrm{~km}$. The time period chosen is 12:00-14:00 on 29 May 2008 when the wind was very intense (table 1 and figure 1 ). The data are received from the Formosat-3 satellite (COSMIC satellites) system and the IGS ground receiver network. The total electron content is measured by the instrument called the Tri-Band Beacon (TBB). TBB is a three frequency radio beacon that radiates coherently at 150,400 , and $1067 \mathrm{MHz}$. When the relative phases of the signals are measured between the COSMIC satellites and ground-based or space-based receivers, the total electron content can be determined (Dymond et al. 2007). These data are recorded and updated every 90 min with approximately 2500 profiles daily.

\section{Method}

\subsection{Theory of Principal Component Analysis (PCA)}

PCA is a frequently used method in data analysis. It has been previously applied in the description of TEC anomalies associated with earthquakes (Lin 2010a, 2010b, 2011, 2012). It is a simple nonparametric method that allows the extraction of relevant data from mixed datasets. Mathematically, the signal $s$ is presented in a transform matrix $D$ of $m$ rows and $n$ columns. In the case of ionospheric analysis the pixilation of the TEC map
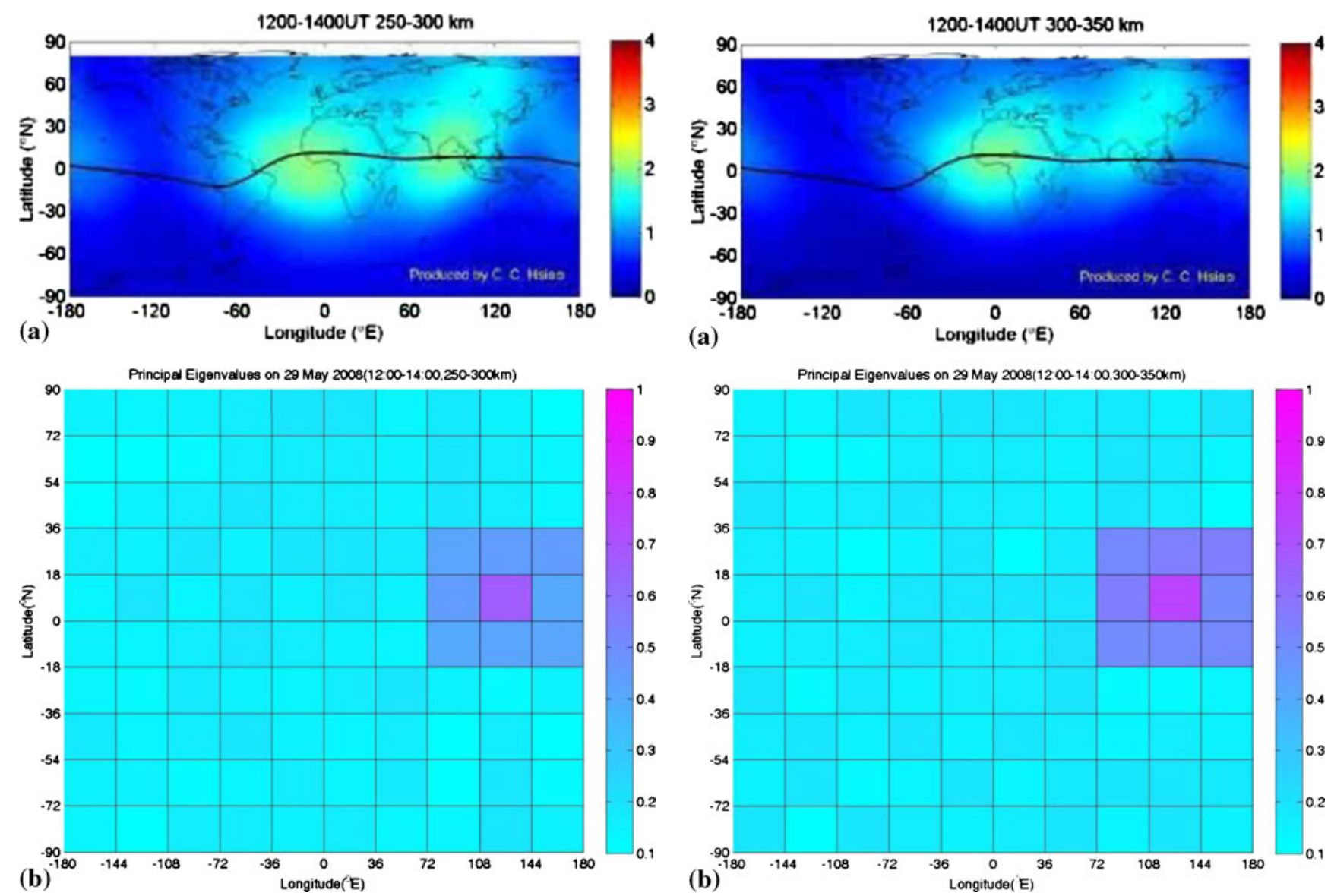

Figure 4. (a) GIM on 29 May at height $250-300 \mathrm{~km}$ for time 12:00-14:00 UT and (b) a colour-coded scale of the magnitudes of principal eigenvalues related to (a).

Figure 5. (a) GIM on 29 May at height $300-350 \mathrm{~km}$ for time 12:00-14:00 UT and (b) a colour-coded scale of the magnitudes of principal eigenvalues related to (a). 
forms a matrix $D$ with $m$ rows and $n$ columns (Londoño et al. 2005):

$$
D=\left[\begin{array}{l}
s_{1 \times 1}, \ldots, s_{1 \times n} \\
\downarrow \\
s_{m \times 1}, \ldots, s_{m \times n}
\end{array}\right] .
$$

For each $n, u$ is a unit vector. $M M^{T} u=\lambda u$ with the largest eigenvalue being $\lambda_{1}$. The eigenvalue $\lambda_{1}$ is called the principal eigenvalue and represents the characteristics of signals.

\subsection{TEC image processing with pixel concept}

Image processing of the Global Ionospheric Maps (figures 2a-7a) was conducted at incremental increases in height of $50 \mathrm{~km}$ from the lower to upper mid-range of the F-layer; i.e., for heights ranging from 150 to $450 \mathrm{~km}$. The processing involved dividing a GIM with a certain height range for a selected time period (12:00-14:00 (UTC) on 29 May 2008) into 100 smaller maps, $36^{\circ}$ in longitude and $18^{\circ}$ in latitude respectively, to analyze TEC anomaly

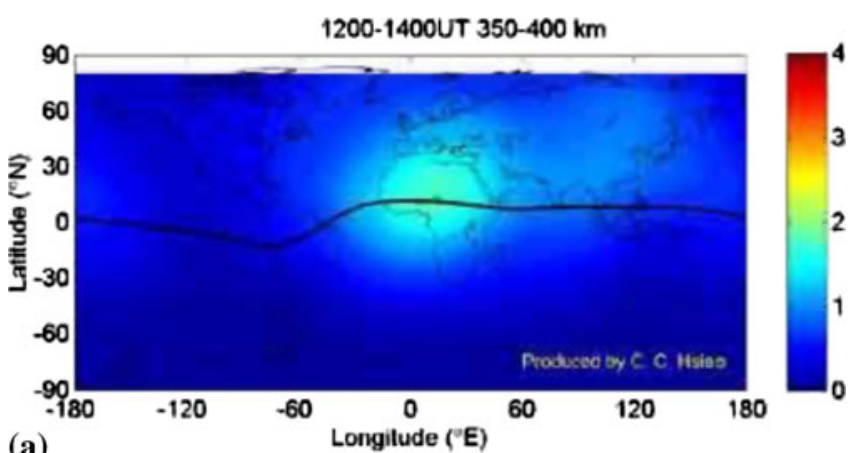

(a)

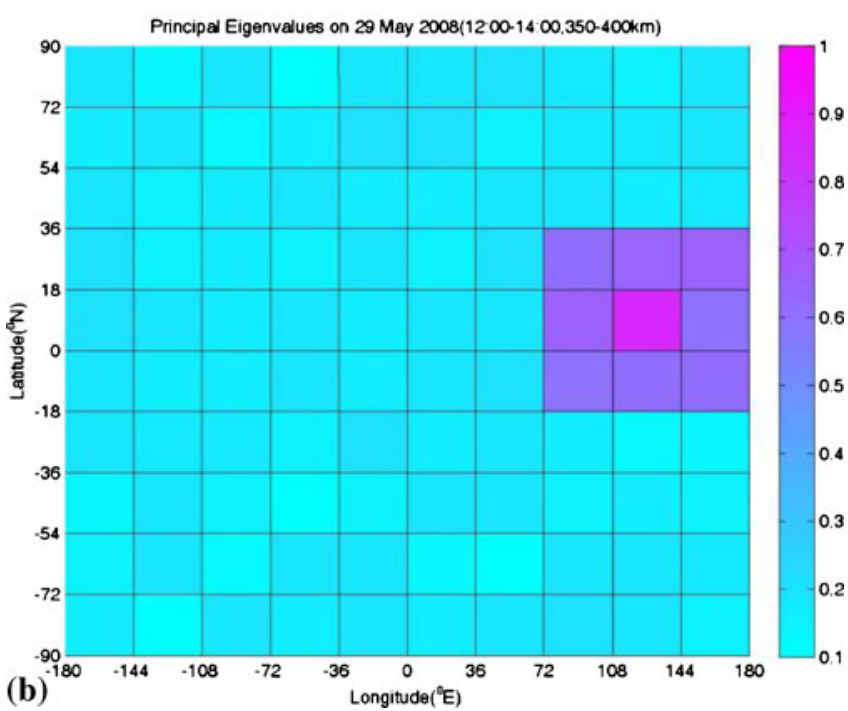

Figure 6. (a) GIM on 29 May at height $350-400 \mathrm{~km}$ for time 12:00-14:00 UT and (b) a colour-coded scale of the magnitudes of principal eigenvalues related to (a).
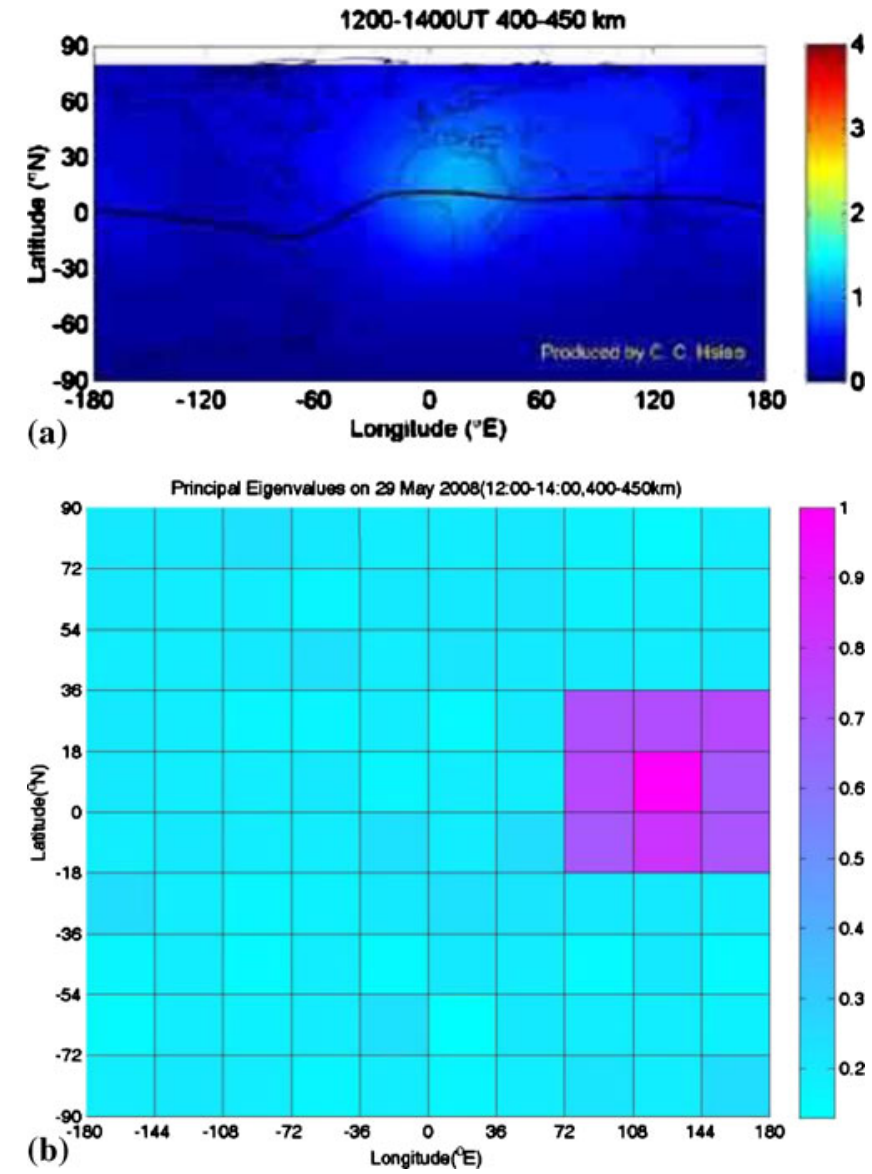

Figure 7. (a) GIM on 29 May at height $400-450 \mathrm{~km}$ at 12:00-18:00 UT and (b) a colour-coded scale of the magnitudes of principal eigenvalues related to (a).

variance with the height range. The smaller maps were constructed at $71 \times 71$ pixels and formed the D matrix of Formula (1) with dimensions $71 \times 71$ (i.e., $m=71, n=71$ ) through image processing using the PCA method (Vasilescu and Terzopoulos 2007; Zhang et al. 2009; Lin 2010a). This allowed for principal eigenvalues to be computed for each of the 100 smaller maps. Image processing and PCA were used and the respective results are given in figures $2(\mathrm{~b})$ to $7(\mathrm{~b})$.

\section{Results}

Figure 2(a) shows the GIM on 29 May for 12:0014:00 UT. Figure 2(b) gives a colour-coded scale of the magnitudes of principal eigenvalues corresponding to figure 2(a). Colour intensity denotes magnitude. From the figure it can be seen that 100 principal eigenvalues are assigned (i.e., each grid in the bottom figures represents a principal eigenvalue). Figures 3-7 show the same approach but for different heights. 

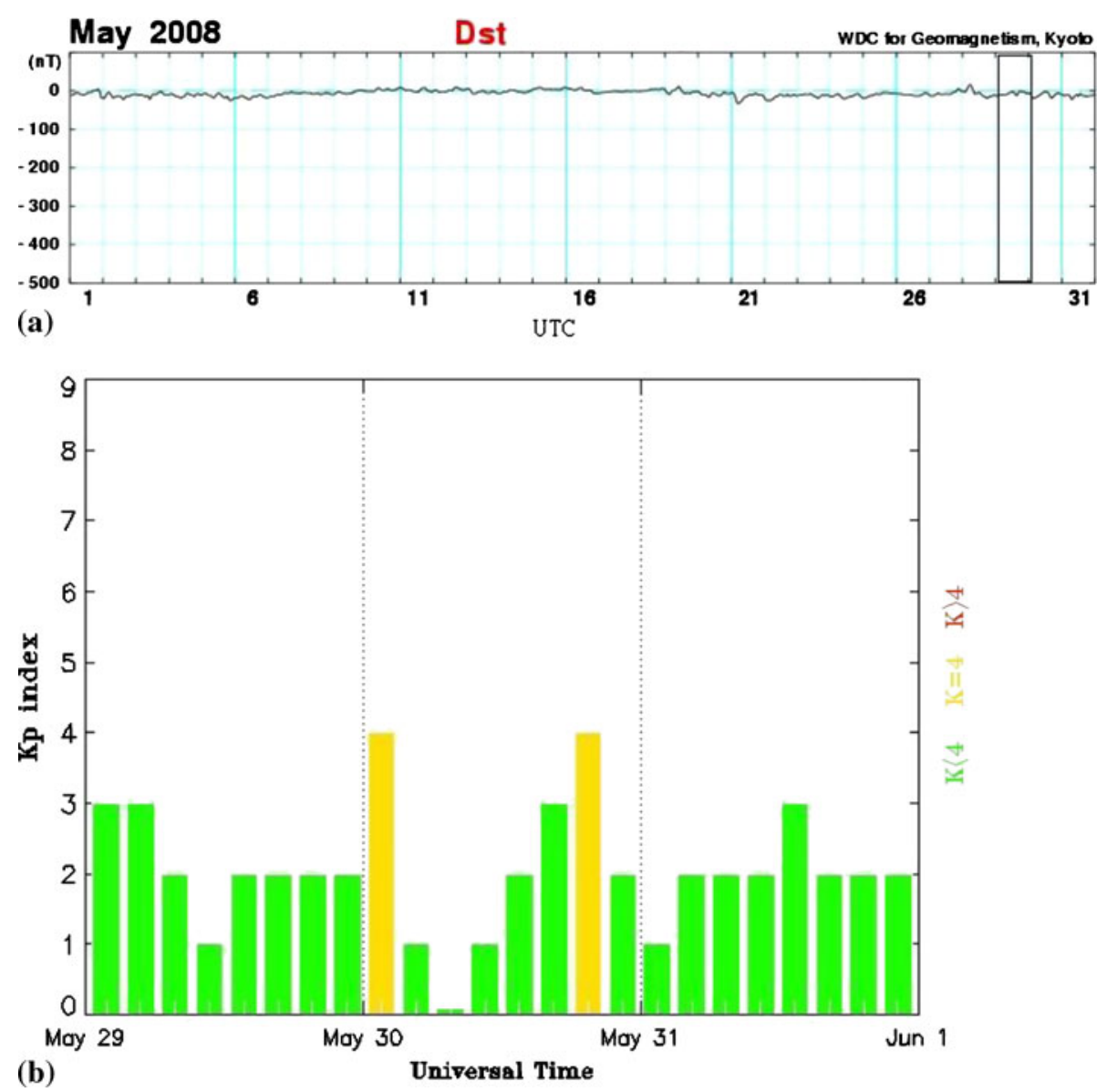

Figure 8. (a) Dst indices in May 2008 (World Data Center for Geomagnetism, Kyoto). The Dst indices on 29 May are within the rectangle. (b) Kp indices from 29 to 31 May 2008 (NOAA Space Center).

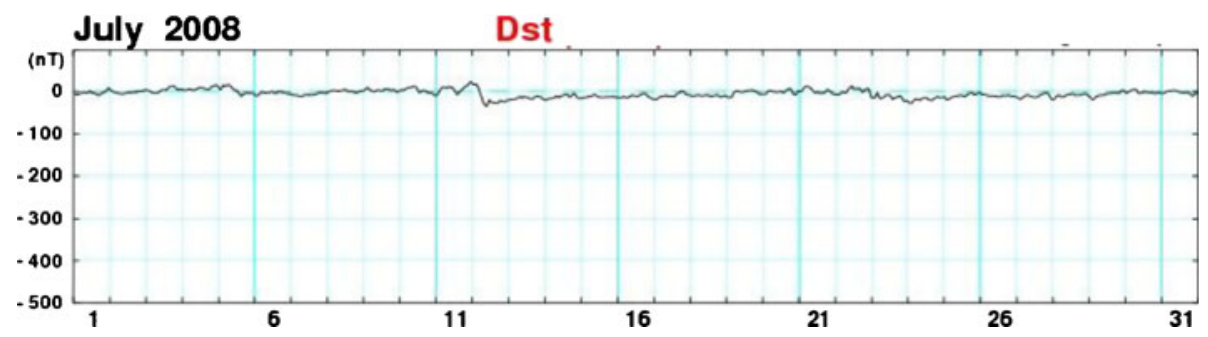

Figure 9. Dst indices in July 2008.

Varying colour intensity, representative of large principal eigenvalues as a mathematical index in the bottom figures of figures $2-7$, shows the existence of a TEC anomaly over the position of typhoon Nakri at $16.2^{\circ} \mathrm{N}, 135.5^{\circ} \mathrm{E}$ (table 1 ). Compared with the results of Lin (2012), which used the same eigenvalue magnitude scale, the TEC anomaly is intense. The anomaly becomes more widespread with height. At 150 to $200 \mathrm{~km}$ it is intense and highly localized while at $450 \mathrm{~km}$ it remains intense over the approximate position of the typhoon's eye but is evidently much greater in absolute size.

The possibility of other factors such as solar flare and geomagnetic effects affecting the results was considered by examining the Dst indices and Kp indices (Elsner and Kavlakov 2001; Mukherjee 1999; Hamilton et al. 1986) in figure 8(a) and 8(b), respectively. Figure 8(a) shows that the Dst index for May was relatively flat indicating that geomagnetic storm activity could not have been responsible for the TEC anomaly. Similar to figure 8(a), 
figure 8(b) shows that geomagnetic storm activity was low during the period being examined (Plotnikov and Barkova 2007; Uyeda et al. 2009; Muella et al. 2009).

\section{PCA for a geomagnetic quiet day} (21 July, 2008)

To better understand whether the detected TEC anomaly was truly related to typhoon Nakri, PCA was applied to the TEC GIM (150-450 km) of 21 July, 2008 for a similar time period (01:0004:00 UT). Like May 29, July 21 was also a geomagnetic quiet day (figure 9, Dst index for 21 July 2008).

The GIMs from 01:00 to 04:00 UT (figures 10a13a) at a time interval of $1 \mathrm{hr}$ were processed using PCA with the same method described in section 2.2 (data source: NASA Global Differential GPS system (GDGPS)), and the maps were derived using data from the 100 real-time GDGPS tracking sites, augmented with additional sites that were

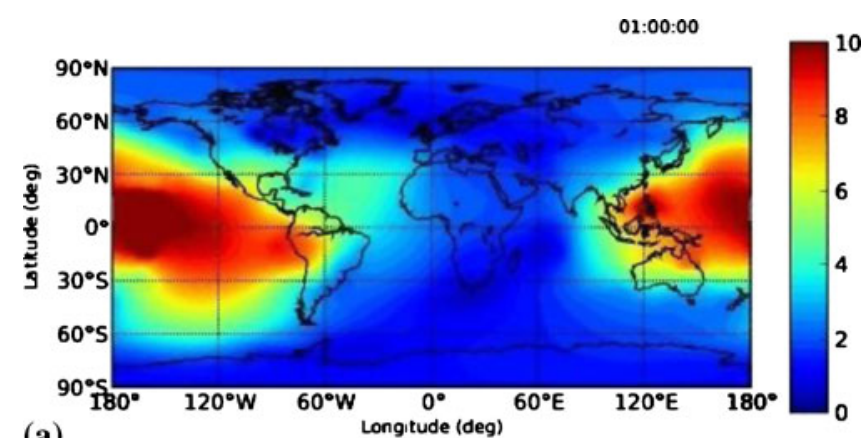

(a)

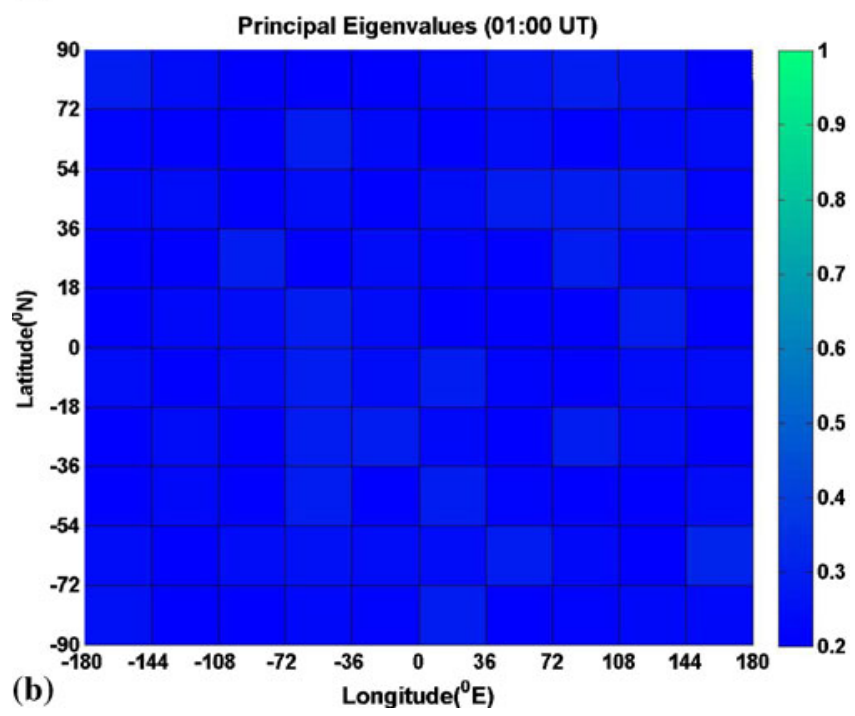

Figure 10. (a) GIM on 21 July at height 150-450 km for the 01:00 UT and (b) a colour-coded scale of the magnitudes of principal eigenvalues corresponding to (a).

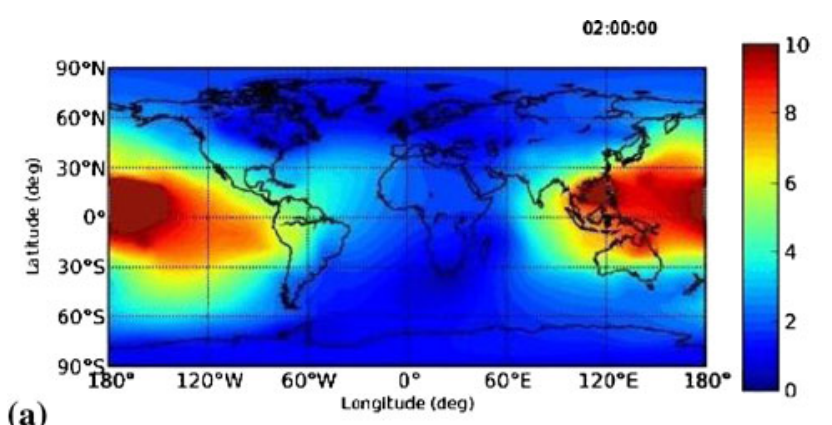

(a)

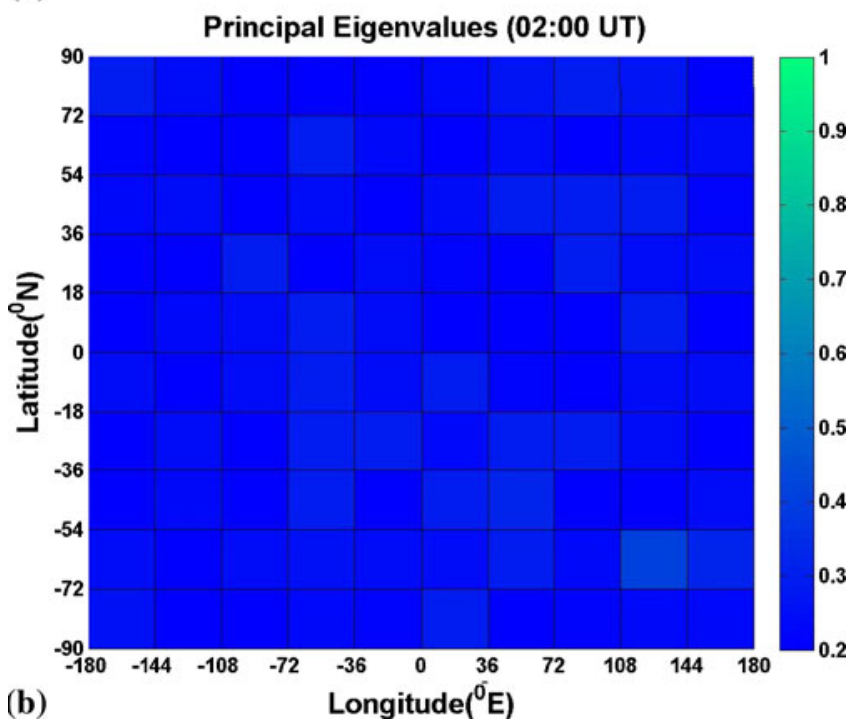

Figure 11. (a) GIM on 21 July at height $150-450 \mathrm{~km}$ for time 02:00 UT and (b) a colour-coded scale of the magnitudes of principal eigenvalues related to (a).

available on an hourly basis, probing the ionosphere with high spatial and temporal resolution. The integrated electron density data along each receiver-GPS satellite link was processed through a Kalman filter in a sun-fixed frame to produce the global gridded maps of TEC). The results are represented in figures $10(\mathrm{~b})-13(\mathrm{~b})$ with the magnitude of principal eigenvalues being small $(<0.5$ in a normalized set). Lin (2010b) showed that principal eigenvalues of greater than 0.5 in a normalized set are representative of a detectable TEC anomaly. This evidence of other TEC anomalies being suppressed due to small magnitudes of principal eigenvalues for a similar time of day on July 21, 2008 supports the TEC anomaly found by PCA on 29 May, 2008 as being related to typhoon Nakri.

\section{Discussion}

Hines' (1960) classic work indicated that acoustic gravity waves generated in the lower atmosphere propagate and are amplified as they rise due to lower atmospheric density with height. Typically during a typhoon these disturbances can be 


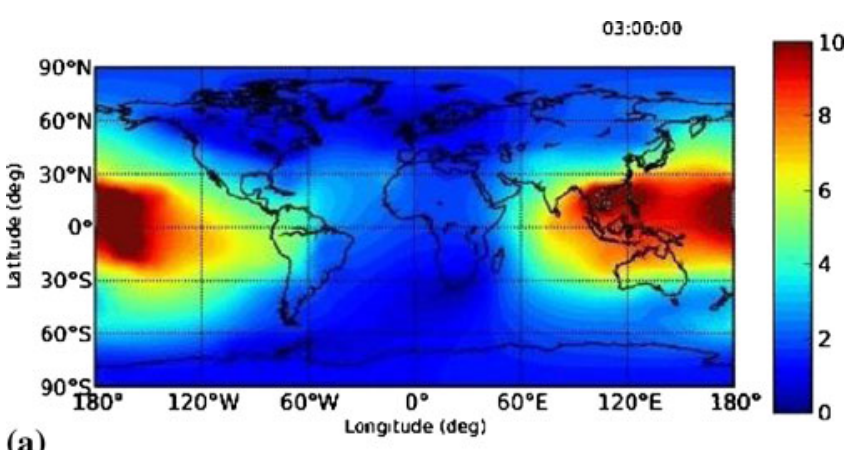

(a)

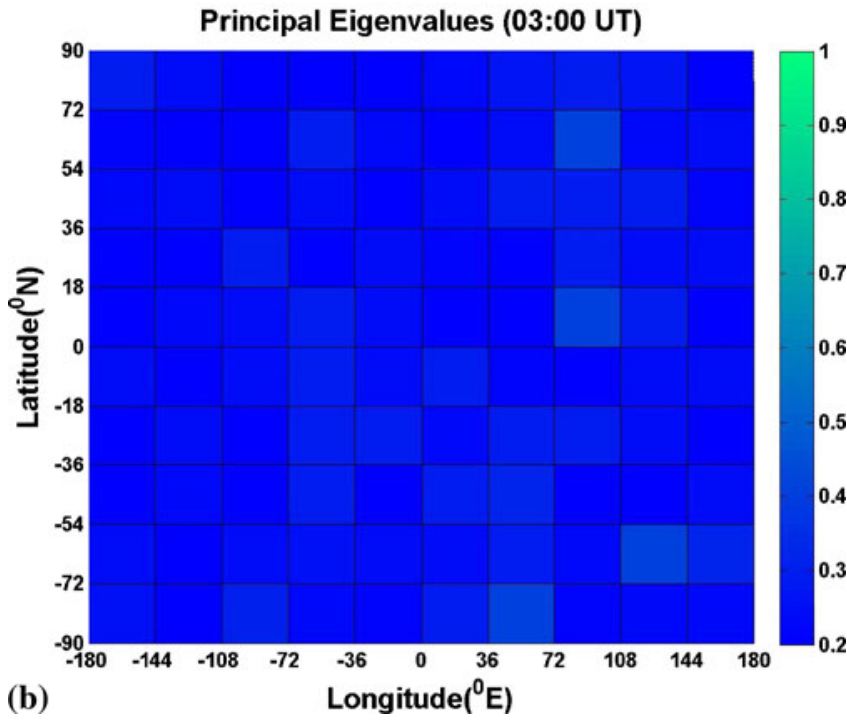

Figure 12. (a) GIM on 21 July at height $150-450 \mathrm{~km}$ for time 03:00 UT and (b) a colour-coded scale of the magnitudes of principal eigenvalues related to (a).

seen as travelling ionospheric disturbances (TIDs). Such disturbances are particularly evident when a typhoon is near coastal regions (Xiao et al. 2007). It is reasonable to think that PCA applied in this paper was able to identify TIDs associated with typhoon Nakri. Other researchers using different methods have made similar findings. Dhaka et al. (2003) investigated intense gravity wave activities in the upper troposphere and lower stratosphere during typhoon 9426. Chun and Kim (2006) proved gravity waves were generated by typhoon Rusa that passed through the Korean Peninsula in 2002. While, in this present paper, examination of typhoon-driven TEC anomalies takes place when typhoon Nakri was most intense, Kim and Chun (2011) showed that the momentum flux of typhoon-generated gravity waves is greatest during the development of a typhoon and in fact this helps the typhoon develop by reducing vertical wind shear. This could suggest a good time window for a future examination of typhoon-driven TEC anomalies caused by gravity waves to cause TEC anomalies through the coupling process between

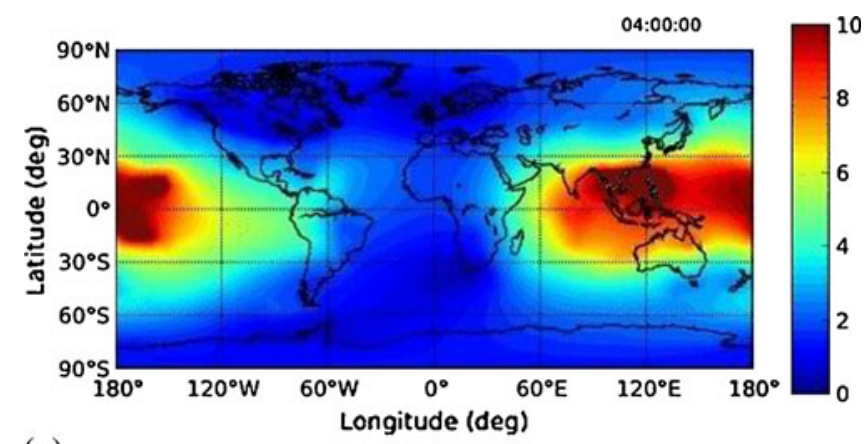

(a)

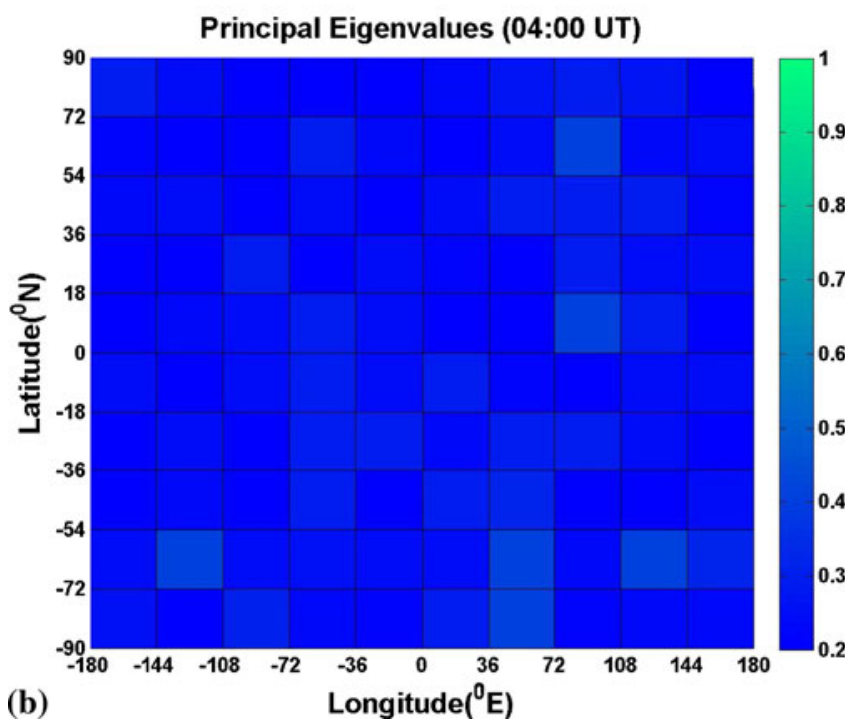

Figure 13. (a) GIM on 21 July at height $150-450 \mathrm{~km}$ for time 04:00 UT and (b) a colour-coded scale of the magnitudes of principal eigenvalues related to (a).

the troposphere and ionosphere. Pulinets (2004) has also discussed the coupling process between the troposphere and ionosphere for rising gravity waves and two recent works have shown such coupling processes through the investigation of earthquakegenerated gravity waves causing TEC anomalies (Lin 2011; Liu et al. 2011). Liu et al. (2011) was able to identify TEC anomalies caused by acoustic gravity waves resulting from the March 11, 2011 great Tohoku earthquake while PCA was also able to detect gravity-wave driven TEC anomalies associated with China's Wenchuan earthquake (Lin 2011).

There are many potential causes of ionospheric TEC anomalies besides gravity waves from lower atmospheric forcings. The most well known causes are solar flare activity and geomagnetic storms. As shown, the Dst and Kp indices indicate geomagnetic quiet conditions on 29 May, 2008; however, it is also important to address the influence geomagnetic activity and other causes of long-term variance may have when applying PCA. Lin (2010b) showed that long-term variance did not affect the results of PCA applied to the detection 
of earthquake-related TEC anomalies. An example of this is given in Lin (2012), which used NLPCA to examine both ionospheric TEC anomalies before the May 12, 2008 Wenchuan earthquake in China and those of an earthquake-free day when a known geomagnetic storm took place. Lin (2012) showed that the magnitude of large principal eigenvalues returned ( $>0.5$ in a normalized set) were relatively small for the geomagnetic storm day compared with those given for the earthquake.

Finally, that PCA can detect typhoon-driven TEC anomalies is an important aspect of this study. Previously, TEC anomalies were detected by deviations from predetermined mean or median values for TEC. PCA gives a pure mathematical basis to the detection of TEC anomalies and can also describe their spatial distribution.

\section{Conclusion}

In this study, principal component analysis (PCA) was used to detect and determine the spatial distribution of a TEC anomaly associated with typhoon Nakri on May 29. Analysis was conducted for the time period 12:00 to 14:00 UT on 29 May 2008. At $150-200 \mathrm{~km}$ the anomaly was intense and highly localized over the approximate position of the typhoon's eye; with height the anomaly remained intense over the typhoon's eye, but was more widespread. It is assumed that the anomaly relates to travelling ionospheric disturbance created by the typhoon due to acoustic gravity waves caused by wind force.

\section{Acknowledgements}

The author is grateful to Prof. Jyh-Shing Roger Jang, Computer Science Dept., National Tsing Hua University, Taiwan, for the idea support and his wife, Liu Cheng-Ling for figure designing.

\section{References}

Bauer S J 1958 Correlation between tropospheric and ionospheric parameters; Geofisica Pura e Applicata 40 235-240.

Bishop R L and Straus P R 2006 Characterizing ionospheric variations in the vicinity of hurricanes and typhoons using GPS occultation measurements, AGU Fall Meeting (San Francisco, Dec. 11-15, 2006); EOS Transactions, American Geophysical Union, 87(52), Suppl. Report No. SA33B-0276.

Chun H Y and Kim S Y 2006 A numerical study on gravity waves generated by typhoon Rusa; Geophys. Res. Abstr. Vol. 8, 06606, SRef-ID: 1607-7962/gra/EGU06-A-06606.

Dhaka S K, Takahashi M, Shibagaki Y, Yamanaka M D and Fukao S 2003 Gravity wave generation in the lower stratosphere due to passage of the typhoon 9426 (Orchid) observed by the MU radar at Shigaraki $\left(34.85^{\circ} \mathrm{N}, 136.10^{\circ} \mathrm{E}\right)$, J. Geophys. Res. 108(D19) 4595 , doi: 10.1029/2003JD003489.

Dymond K F, Bernhardt P A, Rooken C and Syndergaard S 2007 Ionospheric Electron Density Measurements using Cosmic; Plasma Science 2007, ICOPS 2007, IEEE 34th International Conference on Issue Date: 17-22 June 2007, 1005-1005, doi: 10.1109/PPPS.2007.4346311.

Elsner J B and Kavlakov S P 2001 Hurricane intensity changes associated with geomagnetic variation; Atmos. Sci. Lett., doi: 10.1006/asle.2001.0040.

Hamilton D C, Gloeckler G, Ipavich F M, Studemann W, Wilken B and Kremser G 1986 Ring current development during the great geomagnetic storm of February; $J$. Geophys. Res. 93 14,343-14,355.

Hines C O 1960 Internal atmospheric gravity waves at ionospheric heights; Can. J. Phys. 38(11) 1441-1481, doi: 10.1139/p60-150.

Huang Y N, Cheng K and Chen S W 1985 On the detection of acoustic-gravity waves generated by typhoon by use of real time HF Doppler frequency shift sounding system; Radio Sci. 20(4) 897-906, doi: 10.1029/ RS020i004p00897.

Kazimirovsky E 2002 Coupling from below as a source of ionospheric variability: A review; Ann. Geophys. 45(1) $1-29$.

Kazimirovsky E, Herraiz M and De La Morena B A 2003 Effects on the ionosphere due to phenomena occurring below it; Surv. Geophys. 24(2) 139-184, doi: 10.1023/A: 1023206426746.

Kim S Y and Chun H Y 2011 Impact of typhoon-generated gravity waves in the typhoon development; Geophys. Res. Lett. 38 L01806, doi: 10.1029/2010GL045719.

Lin J W 2010a Two-dimensional ionospheric total electron content map (TEC) seismo-ionospheric anomalies through image processing using Principal Component Analysis; Adv. Space Res. 45 1301-1310.

Lin J W 2010b Ionospheric total electron content (TEC) anomalies associated with earthquakes through Karhunen-Loéve Transform (KLT); Terr. Atmos. Ocean. Sci. 21(2) 253-265.

Lin J W 2011 Use of principal component analysis in the identification of the spatial pattern of an ionospheric total electron content anomalies after China's May 12, 2008, M=7.9 Wenchuan earthquake; Adv. Space Res. 47 1983-1989, doi: 10.1016/j.asr.2011.01.013.

Lin J W 2012 Potential reasons for ionospheric anomalies immediately prior to China's Wenchuan earthquake on 12 May 2008 detected by nonlinear Principal Component Analysis; Int. J. Appl. Earth Observation and Geoinformation 14 178-191, doi: 10.1016/j.jag.2011.09.011.

Liu J Y, Tsai H F, Lin C H, Kamogawa M, Chen Y I, Lin C H, Huang B S, Yu S B and Yeh Y H 2010 Coseismic ionospheric disturbances triggered by the ChiChi earthquake; J. Geophys. Res. 115 A08303, doi: 10.1029/2009JA014943.

Liu Y M, Wang J S, Xiao Z and Suo Y C 2006a A possible mechanism of typhoon effects on the ionospheric F2 layer (in Chinese); Chinese J. Space Sci. 26 92-97.

Liu Y M, Wang J S and Suo Y C 2006b Effects of typhoon on the ionosphere; Adv. Geosci. 29 351-360.

Liu J Y, Chen C H, Lin C H, Tsai H F, Chen C H and Kamogawa M 2011 Ionospheric disturbances triggered by the 11 March 2011 M9.0 Tohoku earthquake; J. Geophys. Res. 116 A06319, doi: 10.1029/2011JA016761.

Londoño E G, López L C and Kazmierczak T S 2005 Using the Karhunen-Loève transform to suppress ground roll in seismic data; Earth Sci. Res. J. 9(2) 139-147. 
Mao T, Wang J S, Yang G L, Yu T, Ping J S and Suo Y C 2009 Effects of typhoon Matsa on ionospheric TEC; Chin. Sci. Bull. 55(8) 712-717, doi: 10.1007/s11434009-0472-0.

Muella M T A H, de Paula E R, Kantor I J, Rezende L F C and Smorigo P F 2009 Occurrence and zonal drifts of small-scale ionospheric irregularities over an equatorial station during solar maximum - Magnetic quiet and disturbed conditions; Adv. Space Res. 43(12) 1957-1973.

Mukherjee G K 1999 Storm-associated variations of [OI] $630.0 \mathrm{~nm}$ emissions from low latitudes; Terr. Atmos. Ocean. Sci. 10(1) 265-276.

Plotnikov, Ya I and Barkova E S 2007 Advances in space research nonlinear dependence of Dst and $\mathrm{AE}$ indices on the electric field of magnetic clouds; Adv. Space Res. 40(12) 1858-1862.

Pulinets S A 2004 Ionospheric precursors of earthquakes; Recent advances in theory and practical applications; Terr. Atmos. Ocean. Sci. 15(3) 413-435.

Shen C S 1982 The correlations between the typhoon and the $\mathrm{F}_{\mathrm{O}} \mathrm{F}_{2}$ of ionosphere (in Chinese); Chinese J. Space Sci. 2 335-340.
Sun L, Wan W, Ding F and Mao T 2007 Gravity wave propagation in the realistic atmosphere based on a threedimensional transfer function model; Ann. Geophys. 25 1979-1986.

Xiao Z, Xiao S G, Hao Y Q and Zhang D H 2007 Morphological features of ionospheric response to typhoon; $J$. Geophys. Res. 112 A04304, doi: 10.1029/2006JA011671.

Xu G, Wan W, She C and Du L 2008 The relationship between ionospheric total electron content (TEC) over East Asia and the tropospheric circulation around the Qinghai-Tibet Plateau obtained with a partial correlation method; Adv. Space Res. 42(1) 219-223.

Uyeda S, Kamogawa M and Tanaka H 2009 Analysis of electrical activity and seismicity in the natural time domain for the volcanic-seismic swarm activity in 2000 in the Izu island region, Japan; J. Geophys. Res. 114 B02310.

Vasilescu M A O and Terzopoulos D 2007 Multilinear (Tensor) Image Synthesis, Analysis, and Recognition; IEEE Signal Process. Mag. 119 6p.

Zhang L, Lukac R, Wu X and Zhang D 2009 PCA-based spatially adaptive denoising of CFA images for single-sensor digital cameras; IEEE Trans. Image Process. 18(4) 797-812. 